\title{
A Comparison Framework for Open Source Software Evaluation Methods
}

\author{
Klaas-Jan Stol ${ }^{1}$ and Muhammad Ali Babar ${ }^{2}$ \\ ${ }^{1}$ Lero-University of Limerick, Limerick, Ireland \\ ${ }^{2}$ IT University of Copenhagen, Denmark \\ klaas-jan.stol@lero.ie, malibaba@itu.dk \\ http://www.lero.ie, http://www.itu.dk
}

\begin{abstract}
The use of Open Source Software (OSS) components has become a viable alternative to Commercial Off-The-Shelf (COTS) components in product development. Since the quality of OSS products varies widely, both industry and the research community have reported several OSS evaluation methods that are tailored to the specific characteristics of OSS. We have performed a systematic identification of these methods, and present a comparison framework to compare these methods.
\end{abstract}

Keywords: open source software, evaluation method, comparison framework.

\section{Introduction}

Open Source Software (OSS) is increasingly being integrated into commercial products [1]. Much cited reasons for using OSS are cost savings, fast time-to-market and high-quality software [2]. OSS products can be used as components as an alternative to Commercial Off-The-Shelf (COTS) components. Like COTS evaluation and selection, one of the main challenges of using OSS is evaluation and selection [3]. For that reason, both the research community and industry have proposed evaluation and selection approaches to help practitioners to select appropriate OSS products. However, research has shown that practitioners rarely use formal selection procedures [4]. Instead, OSS products are often selected based on familiarity or recommendations by colleagues [5]. For practitioners it is difficult to choose a suitable evaluation method. We assert that the lack of adoption of these evaluation approaches by practitioners may be a result of a lack of clarity of the OSS evaluation methods landscape. There has been no systematic comparison of the existing OSS evaluation methods. David A. Wheeler lists a number of evaluation methods in [6], but does not provide a thorough comparison of existing evaluation methods. We are aware of only one paper by Deprez and Alexandre [7] that provides an in-depth comparison of two methods, namely QSOS and OpenBRR. However, it is not feasible to extend their approach to compare a large number of methods. In order to improve the state of practice, we decided to systematically identify proposed OSS evaluation methods. Furthermore, we present a comparison framework that can be used to do a systematic comparison of these OSS evaluation methods. 


\section{Identification of Evaluation Methods}

For the identification of the various OSS evaluation methods, we relied on four different sources. Firstly, we selected a large number of publications following a systematic and rigorous search methodology as part of our ongoing extension of a systematic literature review reported in [8]. The search phase of this extension resulted in a repository of approximately 550 papers related to OSS. We screened these papers to identify any OSS evaluation method. We included all papers reporting a method, framework or any other proposed way of evaluating an OSS product. Papers presenting an approach for selecting COTS (as opposed to OSS components only) were also excluded. Secondly, we inspected the "related work" sections of the selected papers. We also noticed that a number of OSS evaluation methods were not reported in research publications, rather only appeared in books or white papers. Since those methods were often referenced in the "related work" sections of many papers, we decided to include those methods in this research. Thirdly, we manually selected publications reported in the proceedings of the five International Conferences on Open Source Systems (2005 to 2009). Lastly, we used the authors' knowledge of the field in order

Table 1. Identified OSS evaluation methods, frameworks and approaches

\begin{tabular}{|c|c|c|c|c|c|}
\hline No. & Name & Year & Source & Orig. & Method \\
\hline 1 & Capgemini Open Source Maturity Model & 2003 & [9] & I & Yes \\
\hline 2 & Evaluation Framework for Open Source Software & 2004 & {$[10]$} & $\mathrm{R}$ & No \\
\hline 3 & $\begin{array}{l}\text { A Model for Comparative Assessment of Open } \\
\text { Source Products }\end{array}$ & 2004 & {$[11,12]$} & $\mathrm{R}$ & Yes \\
\hline 4 & Navica Open Source Maturity Model & 2004 & [13] & I & Yes \\
\hline 5 & Woods and Guliani's OSMM & 2005 & {$[14]$} & I & No \\
\hline 6 & Open Business Readiness Rating (OpenBRR) & 2005 & {$[15,16]$} & $\mathrm{R} / \mathrm{I}$ & Yes \\
\hline 7 & $\begin{array}{l}\text { Atos Origin Method for Qualification and } \\
\text { Selection of Open Source Software (QSOS) }\end{array}$ & 2006 & {$[17]$} & I & Yes \\
\hline 8 & $\begin{array}{l}\text { Evaluation Criteria for Free/Open Source } \\
\text { Software Products }\end{array}$ & 2006 & {$[18]$} & $\mathrm{R}$ & No \\
\hline 9 & A Quality Model for OSS Selection & 2007 & [19] & $\mathrm{R}$ & No \\
\hline 10 & Selection Process of Open Source Software & 2007 & {$[20]$} & $\mathrm{R}$ & Yes \\
\hline 11 & $\begin{array}{l}\text { Observatory for Innovation and Technological } \\
\text { transfer on Open Source software (OITOS) }\end{array}$ & 2007 & $\begin{array}{l}{[21],} \\
{[22]}\end{array}$ & $\mathrm{R}$ & Yes \\
\hline 12 & $\begin{array}{l}\text { Framework for OS Critical Systems Evaluation } \\
\text { (FOCSE) }\end{array}$ & 2007 & [23] & $\mathrm{R}$ & No \\
\hline 13 & Balanced Scorecards for OSS & 2007 & [24] & $\mathrm{R}$ & No \\
\hline 14 & Open Business Quality Rating (OpenBQR) & 2007 & {$[25]$} & $\mathrm{R}$ & Yes \\
\hline 15 & Evaluating OSS through Prototyping & 2007 & {$[26]$} & $\mathrm{R}$ & Yes \\
\hline 16 & $\begin{array}{l}\text { A Comprehensive Approach for Assessing Open } \\
\text { Source Projects }\end{array}$ & 2008 & [27] & $\mathrm{R}$ & No \\
\hline 17 & $\begin{array}{l}\text { Software Quality Observatory for Open Source } \\
\text { Software (SQO-OSS) }\end{array}$ & 2008 & [28] & $\mathrm{R}$ & Yes \\
\hline 18 & $\begin{array}{l}\text { An operational approach for selecting open source } \\
\text { components in a software development project }\end{array}$ & 2008 & [29] & $\mathrm{R}$ & No \\
\hline 19 & QualiPSo trustworthiness model & 2008 & {$[30,31]$} & $\mathrm{R}$ & No \\
\hline 20 & OpenSource Maturity Model (OMM) & 2009 & [32] & $\mathrm{R}$ & No \\
\hline
\end{tabular}


to identify some approaches. We note that we deliberately did not consider any websites (such as web logs) presenting pragmatic "tips for selecting OSS".

Following the abovementioned search process, we identified 20 approaches for OSS evaluation. Table 1 lists the identified OSS evaluation approaches in chronological order of publication. The column "Source" lists references to papers and reports that reported the method, and can be used by interested readers for further investigation. The column "Orig." indicates whether the initiative came from (I)ndustry or from a (R)esearch setting. We considered it to be an industry initiative if it was associated with a company name; otherwise we considered it to be a researchers' initiative. The column "Method" indicates whether it is a well-defined method outlining the required activities, tasks, inputs, and outputs, as opposed to a mere set of evaluation criteria. As can be seen from the table, only half of the approaches that we identified are methods.

\section{A Comparison Framework}

In order to perform a systematic comparison of the selected OSS evaluation methods, we designed a comparison framework called Framework fOr Comparing Open Source software Evaluation Methods (FOCOSEM), which is presented in Table 2.

Table 2. FOCOSEM: a comparison framework for OSS evaluation approaches

\begin{tabular}{|c|c|c|}
\hline Component & Element & Brief description \\
\hline \multirow{4}{*}{$\begin{array}{l}\text { Method } \\
\text { Context }\end{array}$} & Specific goal & What is the particular goal of the method? \\
\hline & $\begin{array}{l}\text { Functionality } \\
\text { evaluation }\end{array}$ & $\begin{array}{l}\text { Is functionality compliance part of the evaluation } \\
\text { method? }\end{array}$ \\
\hline & $\begin{array}{l}\text { Results publicly } \\
\text { available }\end{array}$ & $\begin{array}{l}\text { Are evaluations of OSS products stored in a publicly } \\
\text { accessible repository? }\end{array}$ \\
\hline & $\begin{array}{l}\text { Relation to other } \\
\text { methods }\end{array}$ & $\begin{array}{l}\text { How does the method relate to other methods? I.e. } \\
\text { what methods was this method based on? }\end{array}$ \\
\hline \multirow{2}{*}{$\begin{array}{l}\text { Method } \\
\text { User }\end{array}$} & Required skills & What skills does the user need to use the method? \\
\hline & Intended users & Who are the intended users of the method? \\
\hline \multirow{6}{*}{$\begin{array}{l}\text { Method } \\
\text { Process }\end{array}$} & Method's activities & What are the evaluation method's activities and steps? \\
\hline & Number of criteria & y criteria are used in the evaluation? \\
\hline & Evaluation & What are the method's categories of criteria based on \\
\hline & categories & which the OSS product is evaluated? \\
\hline & Output & What are the outputs of the evaluation method? \\
\hline & Tool support & Is the evaluation method supported by a tool? \\
\hline Method & Validation & $\mathrm{n}$ method been validated? \\
\hline Evaluation & Maturity stage & What is the maturity stage of the evaluation method? \\
\hline
\end{tabular}

FOCOSEM is based on four different sources to justify the selection and formation of its components and elements. The first source is the NIMSAD framework, which is a general framework for understanding and evaluating any methodology [33]. NIMSAD defines four components to evaluate a methodology: the problem context, the problem solver (user), the problem-solving process, and the method's evaluation. Previously, NIMSAD has been used for the development of a number of other comparison 
frameworks in software engineering [34-36]. Hence, we are quite confident about NIMSAD's ability to provide a solid foundation for building an instrument for comparing and evaluating software engineering methods and tools. The second source for FOCOSEM is FOCSAAM, which is a comparison framework for software architecture analysis methods [34]. The third source is a comparison framework for software product line architecture design methods [36]. As a fourth source, we identified differences and commonalities among various OSS evaluation methods. We note that the objective of FOCOSEM is not to make any judgments about different OSS evaluation methods. Instead, we aim to provide insights that may help practitioners to select a suitable OSS evaluation method.

\section{Conclusion and Future Work}

Open Source Software (OSS) products are increasingly being used in software development. In order to select the most suitable OSS product, various evaluation methods have been proposed. Following a systematic and rigorous search of the literature, we identified 20 different initiatives for OSS product evaluation. Furthermore, we have proposed a Framework fOr Comparing Open Source software Evaluation Methods (FOCOSEM). We emphasize that the framework is not intended to make any judgments about the quality of the studied OSS evaluation methods. In future work, we will demonstrate the application of FOCOSEM by comparing the OSS evaluation methods identified in our review. Furthermore, we do not claim our framework is complete; rather, we consider it as a first step towards systematically providing a comparative analysis of OSS evaluation methods. Additional elements can be added to our framework to compare other aspects of the evaluation methods.

\section{Acknowledgements}

This work is partially funded by IRCSET under grant no. RS/2008/134 and by Science Foundation Ireland grant 03/CE2/I303_1 to Lero-The Irish Software Engineering Research Centre (www.lero.ie).

\section{References}

[1] Hauge, Ø., Sørensen, C.-F., Conradi, R.: Adoption of Open Source in the Software Industry. In: Proc. Fourth IFIP WG 2.13 International Conference on Open Source Systems (OSS 2008), Milano, Italy, September 7-10, pp. 211-221 (2008)

[2] Fitzgerald, B.: A Critical Look at Open Source. Computer 37(7), 92-94 (2004)

[3] Maki-Asiala, P., Matinlassi, M.: Quality Assurance of Open Source Components: Integrator Point of View. In: 30th Annual International Computer Software and Applications Conference, 2006. COMPSAC 2006, pp. 189-194 (2006)

[4] Li, J., Conradi, R., Slyngstad, O.P.N., Bunse, C., Torchiano, M., Morisio, M.: Development with Off-the-Shelf Components: 10 Facts. IEEE Software 26(2) (2009) 
[5] Hauge, Ø., Osterlie, T., Sorensen, C.-F., Gerea, M.: An Empirical Study on Selection of Open Source Software - Preliminary Results. In: Proc. ICSE Workshop on Emerging Trends in FLOSS Research (FLOSS 2009), Vancouver, Canada (2009)

[6] Wheeler, D.A.: How to Evaluate Open Source Software / Free Software (OSS/FS) Programs, http://www.dwheeler.com/oss_fs_eval.html (accessed September $8,2009)$

[7] Deprez, J.C., Alexandre, S.: Comparing assessment methodologies for free/open source software: OpenBRR and QSOS. In: Jedlitschka, A., Salo, O. (eds.) PROFES 2008. LNCS, vol. 5089, pp. 189-203. Springer, Heidelberg (2008)

[8] Stol, K., Ali Babar, M.: Reporting Empirical Research in Open Source Software: The State of Practice. In: Proc. 5th IFIP WG 2.13 International Conference on Open Source Systems, Skövde, Sweden, June 3-6, pp. 156-169 (2009)

[9] Duijnhouwer, F., Widdows, C.: Open Source Maturity Model. Capgemini Expert Letter (2003)

[10] Koponen, T., Hotti, V.: Evaluation framework for open source software. In: Proc. Software Engineering and Practice (SERP), Las Vegas, Nevada, USA, June 21-24 (2004)

[11] Polančič, G., Horvat, R.V.: A Model for Comparative Assessment Of Open Source Products. In: Proc. The 8th World Multi-Conference on Systemics, Cybernetics and Informatics, Orlando, USA (2004)

[12] Polančič, G., Horvat, R.V., Rozman, T.: Comparative assessment of open source software using easy accessible data. In: Proc. 26th International Conference on Information Technology Interfaces, Cavtat, Croatia, June 7-10, pp. 673-678 (2004)

[13] Golden, B.: Succeeding with Open Source. Addison-Wesley, Reading (2004)

[14] Woods, D., Guliani, G.: Open Source for the Enterprise: Managing Risks Reaping Rewards. O'Reilly Media, Inc., Sebastopol (2005)

[15] Business Readiness Rating for Open Source, RFC 1 (2005),

http : / / www . openbrr. org

[16] Wasserman, A.I., Pal, M., Chan, C.: The Business Readiness Rating: a Framework for Evaluating Open Source, Technical Report (2006)

[17] Atos Origin: Method for Qualification and Selection of Open Source software (QSOS) version 1.6, Technical Report (2006)

[18] Cruz, D., Wieland, T., Ziegler, A.: Evaluation criteria for free/open source software products based on project analysis. Software Process: Improvement and Practice 11(2) (2006)

[19] Sung, W.J., Kim, J.H., Rhew, S.Y.: A Quality Model for Open Source Software Selection. In: Proc. Sixth International Conference on Advanced Language Processing and Web Information Technology, Luoyang, Henan, China, pp. 515-519 (2007)

[20] Lee, Y.M., Kim, J.B., Choi, I.W., Rhew, S.Y.: A Study on Selection Process of Open Source Software. In: Proc. Sixth International Conference on Advanced Language Processing and Web Information Technology (ALPIT), Luoyang, Henan, China (2007)

[21] Cabano, M., Monti, C., Piancastelli, G.: Context-Dependent Evaluation Methodology for Open Source Software. In: Proc. Third IFIP WG 2.13 International Conference on Open Source Systems (OSS 2007), Limerick, Ireland, pp. 301-306 (2007)

[22] Assessment of the degree of maturity of Open Source open source software, http: / /www.oitos.it/opencms/opencms/oitos / Valutazione_di_prodotti/Modello1.2.pdf

[23] Ardagna, C.A., Damiani, E., Frati, F.: FOCSE: An OWA-based Evaluation Framework for OS Adoption in Critical Environments. In: Proc. Third IFIP WG 2.13 International Conference on Open Source Systems, Limerick, Ireland, pp. 3-16 (2007) 
[24] Lavazza, L.: Beyond Total Cost of Ownership: Applying Balanced Scorecards to OpenSource Software. In: Proc. International Conference on Software Engineering Advances (ICSEA) Cap Esterel, French Riviera, France, p. 74 (2007)

[25] Taibi, D., Lavazza, L., Morasca, S.: OpenBQR: a framework for the assessment of OSS. In: Proc. Third IFIP WG 2.13 International Conference on Open Source Systems (OSS 2007), Limerick, Ireland, pp. 173-186 (2007)

[26] Carbon, R., Ciolkowski, M., Heidrich, J., John, I., Muthig, D.: Evaluating Open Source Software through Prototyping. In: St.Amant, K., Still, B. (eds.) Handbook of Research on Open Source Software: Technological, Economic, and Social Perspectives (Information Science Reference, 2007), pp. 269-281 (2007)

[27] Ciolkowski, M., Soto, M.: Towards a Comprehensive Approach for Assessing Open Source Projects. In: Software Process and Product Measurement. Springer, Heidelberg (2008)

[28] Samoladas, I., Gousios, G., Spinellis, D., Stamelos, I.: The SQO-OSS Quality Model: Measurement Based Open Source Software Evaluation. In: Proc. Fourth IFIP WG 2.13 International Conference on Open Source Systems (OSS 2008), Milano, Italy (2008)

[29] Majchrowski, A., Deprez, J.: An operational approach for selecting open source components in a software development project. In: Proc. 15th European Conference, Software Process Improvement (EuroSPI), Dublin, Ireland, September 3-5 (2008)

[30] del Bianco, V., Lavazza, L., Morasca, S., Taibi, D.: Quality of Open Source Software: The QualiPSo Trustworthiness Model. In: Proc. Fifth IFIP WG 2.13 International Conference on Open Source Systems (OSS 2009), Skövde, Sweden, June 3-6 (2009)

[31] del Bianco, V., Lavazza, L., Morasca, S., Taibi, D.: The observed characteristics and relevant factors used for assessing the trustworthiness of OSS products and artefacts, Technical Report no. A5.D1.5.3 (2008)

[32] Petrinja, E., Nambakam, R., Sillitti, A.: Introducing the OpenSource Maturity Model. In: Proc. ICSE Workshop on Emerging Trends in Free/Libre/Open Source Software Research and Development (FLOSS 2009), Vancouver, Canada, pp. 37-41 (2009)

[33] Jayaratna, N.: Understanding and Evaluating Methodologies: NIMSAD, a Systematic Framework. McGraw-Hill, Inc., New York (1994)

[34] Ali Babar, M., Gorton, I.: Comparison of Scenario-Based Software Architecture Evaluation Methods. In: Proc. 11th Asia-Pacific Software Engineering Conference (APSEC 2004), Busan, Korea, November 30-December 3, pp. 600-607 (2004)

[35] Forsell, M., Halttunen, V., Ahonen, J.: Evaluation of Component-Based Software Development Methodologies. In: Proc. Fenno-Ugric Symposium on Software Technology, Tallin, Estonia, pp. 53-63 (1999)

[36] Matinlassi, M.: Comparison of software product line architecture design methods: COPA, FAST, FORM, KobrA and QADA. In: Proc. 26th International Conference on Software Engineering (ICSE), Edingburgh, Scotland, United Kingdom, May 23-28 (2004) 